\title{
Trend and Determinants of Unmet Need for Family Planning Services among Currently Married Women and Sexually Active Unmarried Women Aged I5-49 in Nigeria (2003-2013)
}

\author{
Ayodeji Babatunde Oginni ${ }^{1 a}$, Babatunde Aloysius Ahonsi ${ }^{b}$, and Sylvia Adebajo ${ }^{a}$ \\ aPopulation Council, Abuja, Nigeria \\ bUnited Nations Population Fund, Accra, Ghana
}

\begin{abstract}
Data from three consecutive Nigeria Demographic and Health Surveys (2003, 2008 and 2013) were analysed. The results show that unmet need for FP declined between 2008 and 2013 to a level less comparable with the situation in 2003. The significant determinants of unmet need for FP included age, marital status, education, religion, current work status, decision-making on spending personal earnings, gender of household heads, household wealth status, number of living children (including current pregnancy), rural-urban residence, home visit by FP workers and recent exposure to FP messages via mass media. It is therefore necessary that FP programmers continue to develop specific responses that address the barriers to contraceptive use.
\end{abstract}

Keywords: Unmet Needs, Family Planning, Women, Nigeria, Trend \& Determinants

\section{Résumé}

Cette étude a analysé les données démographiques et de santé au Nigeria entre 2003 et 2013. Les résultats montrent que les besoins en matière de PF ont diminué entre 2008 et 2013 par rapport à 2003. Les déterminants les plus important sont l'âge, l'état matrimonial, l'éducation, la religion, le statut de travail actuel, la prise de décision dépenser les revenus personnels, le sexe du chef du foyer, l'état de la richesse des ménages, nombre des enfants vivant, residence rurale - urbaine, visite à domicile par les travailleurs de PF et l'exposition aux messages de PF via les médias de masse. En conclusion, programmeurs PF continuent à élaborer des réponses spécifiques qui répondent aux barriere de contraception.

Mots clés: besoins, planification de la famille, déterminants

\footnotetext{
${ }^{1}$ Corresponding author: Oginni, Ayodeji Babatunde Address for correspondence: Ayodeji Oginni, Population Council, House 4, No 16 Mafemi Crescent, Utako District, Abuja, Federal Capital Territory, Nigeria aoginni@popcouncil.org; ogilex222@yahoo.com; ogilex222@gmail.com +2347064185207; +23480111231573
} 


\section{Introduction}

Achievement of desired number and healthy timing of births have important benefits for women, families, and societies (Darroch and Singh, 2013), especially with regards to health, population growth and development (Pallikadavath and Stones, 2006). Meeting unmet need for FP has immense potential for costs saving in most countries in education and maternal health and in averting maternal death during childbirth by reducing the number of pregnancies and induced abortions (Moreland and Talbird, 2006). Also, simply meeting unmet need for FP could go a long way towards lowering fertility (UNFPA, 20I3). Recent evidence shows that serving all women in developing countries who currently have an unmet need for modern methods can prevent an additional 54 million unintended pregnancies, including 21 million unplanned births, 26 million abortions (of which 16 million would be unsafe) and seven million miscarriages; this would also prevent 79,000 maternal deaths and I.I million infant deaths (Singh and Darroch, 2012). Slowing population growth by addressing unmet need for contraception as part of reproductive health programmes that respect and protect human rights could also help to ease pressures on biodiversity while empowering women and their families (Population and Sustainability Network [PSN], 20I2). However, in spite of these huge health and economic benefits, contraceptive use remains low in countries with high fertility, most of which are located in sub-Saharan Africa (SSA)where contraceptive prevalence averages at $22 \%$ and social norms still favour large families. Ironically, many of these countries have policies to lower fertility (UN Department of Economic and Social Affairs, 2007).

Globally, the number of women desiring to prevent pregnancy and by extension needing effective contraception has increased substantially, from 716 million (54\%) of $132 \mathrm{I}$ million in 2003, to 827 million (57\%) of I 448 million in 2008, and 867 million (57\%) of 1520 million in 2012. Most of this increase ( 108 million) was attributable to population growth (Darroch and Singh, 2013). At present, over 200 million women particularly in the low income countries are desirous of delaying or preventing pregnancy, but are not using effective or modern method of contraception (Bongaarts et al., 2012, UNFPA, 20I3). Unmet need in sub-Saharan Africa is high, with nearly three of every 10 women in the region i.e. over 30 million women having unmet need for modern contraception. In West Africa, the average unmet need for modern contraception is $34 \%$, and in East and Southern Africa, $31 \%$. Nineteen of the 31 sub-Saharan African countries, including Senegal, Ethiopia, Malawi, Uganda and Zambia, have levels of unmet need for modern contraception ranging between $30 \%$ and $40 \%$, and six countries-Congo, Gabon, Ghana, Comoros, Togo and Rwanda-have levels that exceed $40 \%$. In contrast to other regions which have seen levels of unmet need for modern contraception fall, there has been little or no reduction in unmet need in the past decade in sub-Saharan Africa.

Given that FP funding has until very recently been limited and in SSA, focused on a few highly populous countries including Nigeria, Ethiopia, and Tanzania (The William and Flora Hewlett Foundation and Redstone Strategy Group LLC, 2008) an understanding of how levels of unmet need change over time can help countries set service priorities right (Cleland et al., 2006, UNFPA and PATH, 2008). It is necessary to understand the distribution of unmet needs of FP among women in a country like Nigeria with an estimated population of 177 million people, population growth rate of $2.5 \%$ and a total fertility rate (TFR) of 5.5 children born per woman (The Central Intelligence Agency, 2013). There has been a slight decline in the total fertility rate in Nigeria from 5.9 reported in the 199 I census, to 5.7 in 2003 and 2008, and further to 5.5 in 2013. During the same period, contraceptive prevalence among currently married women in the country has increased from $6.0 \%$ in 1990 to $12.6 \%$ in 2003 , $14.6 \%$ in 2008 and to $15.1 \%$ reported in 2013 (National Population Commission (NPC) [Nigeria] and ICF International, 20I4). A recent survey in Nigeria reported that $16.1 \%$ (Spacing-11.9\% and Limiting-4.2\%) of currently married women and $12.7 \%$ (Spacing-9.7\% and Limiting-3.1\%) of all women have unmet need for FP (National Population Commission (NPC) [Nigeria] and ICF International, 20I4). Population groups currently reported to be at high risk of unmet need for FP in Nigeria include women in the North Central zone, unmarried women, women with primary education or no education, and women in the middle and fourth wealth quintiles (National Population Commission (NPC) [Nigeria] and ICF International, 20I4).

The aim of this study was to examine the trend and determinants of unmet need for FP among currently married women and sexually active unmarried women of reproductive age 15-49 in Nigeria over a period of 10 years (2003-20I3).

\section{Literature review and Theoretical framework}

This study was based on the theoretical postulation that unmet need for FP among women of reproductive age is a function of demographic and socio-economic factors, place of residence, knowledge of FP methods, fertility-related factors and exposure to FP-related interventions. 
Demographic and Socio-economic Factors

Many studies have identified a number of demographic and socio-economic determinants of unmet need for FP among women. These include age (Hailemariam and Haddis, 20II, Ojakaa, 2008, Gardella, 2006), marital status (Westoff, 2006), education (Acacio-Claro and Borja, 2010, Ali and Okud, 2013, Arshad and Masood, 2010, Ojakaa, 2008, Westoff, 2006, Westoff, 20I2), religion (AlJawadi and Al-Bakry, 2010, Mills et al., 2010, Westoff, 2012), occupation(Ali and Okud, 2013, Ojakaa, 2008), inequalities and household wealth (Health Policy Initiative Task Order I Constella Futures, 2007, Mills et al., 2010, Ojakaa, 2008, Westoff, 2012), household headship (male or female), women's autonomy, etc. Findings on age as a determinant of unmet need among women are equivocal. Whilst some studies (United Nations, 20II, Ojakaa, 2008), found unmet need to be more prevalent among adolescents and young women, the converse was reported in other studies (Klijzing, 2000, Gardella, 2006, Hameed et al., 20II). In Hungary, unmet need was reportedly higher among women in marital unions than among those in less formal relationships (Klijzing, 2000) perhaps as a result of opposition from husbands or partners (Khan Shane et al., 2008, Westoff, 2012). Although, the association between unmet need for FP and marital status is not clear in the literature. This is partly because unmarried women are often excluded in studies as a result of difficulties encountered in collecting reliable data (Casterline and Sinding, 2000, Westoff, 2006). There are several problems associated with measuring unmet need for FP among unmarried women, which include uncertainties in the quality of reports of the frequency and timing of sexual activity especially among unmarried teenagers, the assumption that unmarried women who report sexual activity but no contraceptive use are averse to the idea of becoming pregnant-an assumption that seems reasonable for most but certainly not for all such women (Westoff, 2006) and the existence of barriers to services faced by unmarried young people (Bernstein and Edouard, 2007). It is believed that available statistics on unmet need for FP might underestimate the true demand for FP among unmarried women (Kols, 2008) perhaps because of women who are not sexually active. Confining estimates to sexually active women also runs the risk of overestimation of unmet need because not all these women may desire to avoid getting pregnant (Westoff, 2006). However, mounting evidence emerging from studies around the world has shown consistent declines in unmet need among unmarried sexually active women (Westoff, 2012, Westoff, 2006).
With respect to educational status, findings from previous studies have reported that educational level plays an important role in shaping unmet need for FP (Hailemariam and Haddis, 20II, Acacio-Claro and Borja, 2010, Ali and Okud, 2013, Ojakaa, 2008). While in Eastern Sudan, higher education among women and their husbands is significantly associated with unmet need for FP (Ali and Okud, 20I3); in Ethiopia, women with unmet need for both spacing and limiting are more likely to have lower levels of education (Hailemariam and Haddis, 20I I). Evidence from the Philippines also shows that educational status could modify the association between attitudes and unmet need for FP even after controlling for the effects of age, the number of living children, knowledge and access to FP services (Acacio-Claro and Borja, 20I0). Generally in SSA, most of the reported decline in unmet need are among women with at least primary education (Westoff, 2006).

Studies have identified religious beliefs among the main reasons offered by women with unmet need for not using modern contraception (Mills et al., 2010, Al-jawadi and Al-Bakry, 2010, Westoff, 2012). Looking at occupation, findings from studies in Ethiopia (Hailemariam and Haddis, 20II), Kenya (Ojakaa, 2008) and Eastern Sudan (Ali and Okud, 2013) show that unmet need decreases with women's employment. For instance, housewives in Eastern Sudan (Ali and Okud, 2013) and women with no work other than household chores in Ethiopia (Hailemariam and Haddis, 20II) were significantly more likely to have unmet needs. The effects of inequality, poverty and wealth on unmet need are also widely discussed in the literature. There is mounting evidence that in a given country, the poor may tend to experience higher levels of unmet need for family planning as their desire to limit or space births increases, while wealthier groups experience diminishing unmet need due to their rising FP use (Health Policy Initiative Task Order I Constella Futures, 2007). In some countries such as Benin, Chad, Mali, and Nigeria, women in the wealthiest quintile have higher unmet need than the women in lower quintiles, whereas in other countries such as Bolivia, Ghana, Togo, and Zimbabwe, the patterns are reversed (Mills et al., 20I0). According Mills et al., the reasons for these patterns are essentially the same as for differences among countries at different stages of fertility decline because countries in which unmet need increases with increasing wealth tend to be in the earlier stages of declining desired family size, which declines first in urban areas, among more educated women, and among wealthier households. As FP programs and other providers are at first not able to meet the increased demand for contraceptives or address concerns about health and side effects, unmet need increases in the wealthier 
quintiles, while it remains low in the poorest quintiles where demand for FP remains low.

Household headship may also influence unmet need for FP among women. Expectedly, in femaleheaded households, women could talk more easily with female head of a household about their reproductive health challenges and female household heads could better understand female health problems, and thus encourage women to visit health facilities (Adhikari and Podhisita, 2010). In fact, a study in Sri Lanka found that women in femaleheaded households used health services more frequently than did those in male-headed ones (Wickrama, 1990). Also, women's autonomy in decision making or control over household resources (ability to keep money aside) has a significant positive effect on women's demand for and utilization of health products and services such as contraceptives, prenatal and perinatal care services among others (Maitra, 2004, Adhikari and Podhisita, 2010, Dyson and Moore, 1983).

Place of Residence

The two widely used indicators in the literature for place of residence are region of residence and urban-rural residence. A number of studies (Hailemariam and Haddis, 20I I, Khan Shane et al., 2008, Arshad and Masood, 2010) have linked these two indicators with differentials in unmet need for FP. For example, two of these studies found both unmet need for spacing and limiting to be higher in rural areas (Arshad and Masood, 2010, Hailemariam and Haddis, 20I I); and another in Uganda, found the levels of unmet need to be much higher among women living in the Northern region than in the South.

\section{Knowledge of FP methods}

Evidence from scientific literature shows the consistent link between knowledge of FP and unmet need. (Hailemariam and Haddis, 20I I, Prata, 2009). A cross-sectional study conducted in Monsul City, North of Iraq identified lack of knowledge as one of the most important reasons for unmet need (AlJawadi and Al-Bakry, 2010). Similarly, in Ethiopia, women with unmet need for both spacing and limiting were more likely to have lower knowledge level of FP methods (Hailemariam and Haddis, 20I I).

\section{Exposure to FP-related interventions}

Exposure to FP related interventions includes contact with FP providers, exposure to FP information through media, peer groups, schools, or community leaders, health insurance schemes, etc. (Hailemariam and Haddis, 20II, Ojakaa, 2008, National Population Commission [NPC] and ICF Macro, 2009, Dutta Arin and Charles Hongoro, 2013). Findings emanating from studies linking exposure to FP-related interventions and unmet need of FP in SSA have been conflicting. Whereas, a study in Ethiopia reported that women with unmet need for both spacing and limiting were more likely to have never been visited by a FP worker (Hailemariam and Haddis, 20I I); in Kenya, contact with health services was significantly linked to unmet need for FP. Thus, implying that although contact with health services could generate demand for FP, it may not necessarily meet the demand (Ojakaa, 2008). Interestingly, a cross-country study found that media messages promoting FP seemed less important except in West and Middle Africa and other poorer countries (Westoff, 2012).

Prata (Prata, 2009) suggested four critical steps that should be taken to increase access to FP in resource-poor settings. Of these steps, three [(i) to ensure that contraception is genuinely affordable to the poorest families; (ii) to ensure supply of contraceptives by making FP a permanent line item in healthcare system's budgets and (iii) to take immediate action to remove barriers hindering access to FP methods] are core components of health insurance schemes. Health insurance can be a good mechanism for pooling resources in advance for covering the costs, and potentially, a financially sustainable way of covering a large number of people, especially when the costs also involve less frequent and more expensive health services, such as those requiring hospitalization (Dutta Arin and Charles Hongoro, 2013). In Nigeria, one of the benefits of the National health insurance scheme is preventive care, which includes FP (Adesina, 2009).

\section{Fertility-Related Factors}

A number of studies have also shown that changes in unmet need can be influenced by a variety of factors related to fertility preferences (Sharan et al., 20II) and parity (Hailemariam and Haddis, 20II, lgwegbe et al., 2009, Khan Shane et al., 2008, Ojakaa, 2008). Studies from Uganda and Kenya, have demonstrated that total unmet need was higher among women with a higher number of living children (Khan Shane et al., 2008, Ojakaa, 2008).

\section{Data and Methods}

\section{Study Design and Data}

This study was based on secondary analyses of data from three consecutive Nigeria Demographic and Health Surveys (NDHS) conducted in 2003, 2008 and 2013. The Nigeria Demographic Health Surveys are national surveys of women aged 15-49 and men aged 15-59. The data are intended to furnish programme managers and policymakers with detailed public health information.

This study population comprised currently married women and sexually active unmarried women (i.e. unmarried women who have had sexual intercourse within 30 days preceding the survey) 
aged 15-49 who were fecund, pregnant or amenorrhoeic. The three datasets contain individual sampling weights for women, which were obtained by further correction for women's individual nonresponse based on household sampling weights (National Population Commission (NPC) [Nigeria] and ICF International, 20I4). The datasets were pooled giving a total of 49209 respondents comprising 4448 from 2003 NDHS, 20936 from 2008 NDHS and 23825 from 2013 NDHS.

\section{Key Variables}

There were three dependent variables in this study -unmet need for spacing, unmet need for limiting and total unmet need for FP. In the NDHS (National Population Commission (NPC) [Nigeria] and and ORC Macro, 2003, National Population Commission [Nigeria], 2000, National Population Commission [NPC] and ICF Macro, 2009), women who reported not wanting more children (limiters), or wanting to wait for two or more years before having another child (spacers), but were not using contraception, were categorized as having an unmet need for FP. Pregnant women were considered to have unmet need for spacing or limiting if their pregnancy was mistimed or unwanted, respectively. Similarly, amenorrhoeic women were classified as having unmet need if their last birth was mistimed or unwanted. Women with unmet need for FP and those who were using contraception together constituted the total demand for FP. This information was important not only to determine the total demand for FP but to measure the percentage of demand satisfied.

The independent variables were: age, marital status, educational status, religion, current work status, decision-making on spending of personal earnings, gender of household headship, household wealth index, number of living children (including current pregnancy), rural-urban place of residence, north-south region of residence, knowledge of a modern FP method, visit to health facilities in the last 12 months, visit from FP workers in the last 12 months, been told of FP at health facilities in the last
12 months, and been exposed to FP messages via mass media in the last few months. The selection of the independent variables was informed by their documented significant association with unmet need for FP in the literature and their availability in the dataset.

\section{Statistical analysis}

The data were first summarized with percentages. Thereafter, bivariable analysis was conducted using chi-square test to assess associations between dependent and independent variables within and across the three survey years. All the independent variables including the survey years were further subjected to multivariable analysis using enter method to identify the significant determinants of unmet need for FP while controlling for the extraneous influence of the survey years using a pooled dataset. Log-binomial regression model was used for the multivariable analysis to obtain the prevalence ratio (PR) with $95 \%$ Confidence Intervals (Cl). All analyses were conducted on weighted (individual sampling weights for women) data using Stata/SE II .0 for Windows(StataCorp LP, 2009).

\section{Results}

\section{General description of the study population}

Table I presents information about the study population. Generally across the three survey years, over $60 \%$ of the study population were aged $25-49$ years; majority (>90\%) were currently married, more than half had any formal education and at least $50 \%$ were Muslims. Also, about two-thirds of the study population were currently working and less than one-third admitted having autonomy to take decisions on spending personal earnings. Majority $(>80 \%)$ of the women resided in male-headed households and about two-fifths resided in poor households. Over $50 \%$ of the women had three or more living children. Also, about two-thirds of respondents were rural dwellers and more than half resided in the Northern regions of Nigeria. 
Table I. Respondents' distribution according to some demographic and socio-economic characteristics

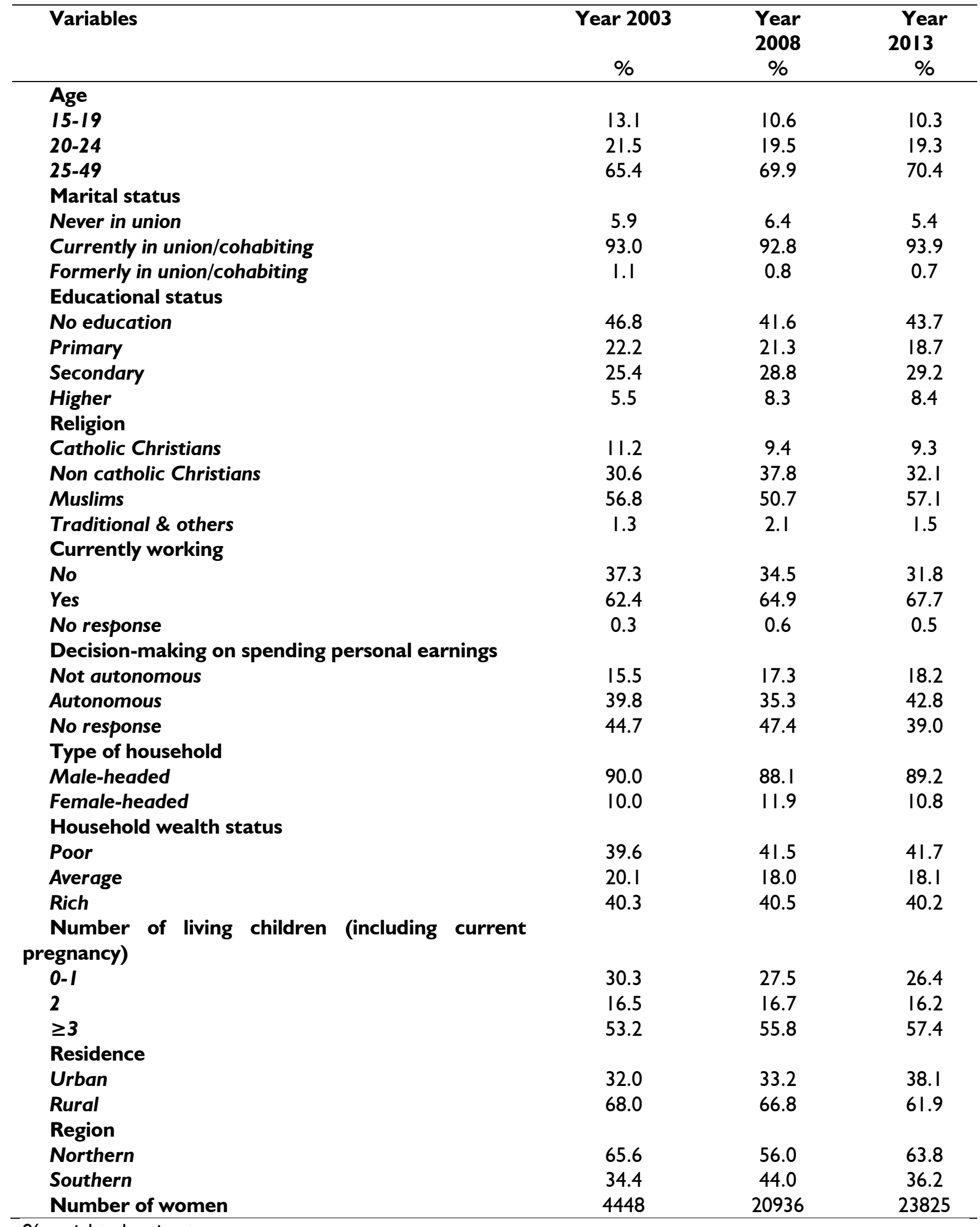

$\%$ weighted estimate

According to Table 2, proportion of women with knowledge of modern FP method in each year was high (>70\%). In 2003 , about $40 \%$ of the women visited health facilities in the last 12 months, while in 2008 and 2013 , the proportions reduced to $27 \%$ and
$30 \%$ respectively. Few $(6 \%)$ of the women were visited by FP workers in 2003 and 2008 respectively increasing to $11 \%$ in 2013 . Also in the three rounds of the survey, at least one in 10 women reported hearing about FP at health facilities in the last 12 
months. Exposure to FP messages via mass media was relatively low as more than $50 \%$ of the women had never been exposed to FP messages via mass media in the last few months.

The level of unmet need for spacing among women increased from $16.3 \%$ in 2003 to $18.9 \%$ in
2008 but declined to $14.6 \%$ in 2013 . Unmet need for spacing or limiting pregnancies decreased from $6 \%$ in 2003 to $4.5 \%$ in 2013 . Total unmet need for FP increased between 2003 (22.3\%) and 2008 (24.9\%) but declined to $19.1 \%$ in 2013 (Table 2). 
Table 2. Respondents' knowledge of FP and exposure to FP interventions in the last 12 months Variables Year 2003 Year 2008 Year 2013

$\%$

Knowledge of modern FP method

No knowledge

Knowledge of folkloric/traditional

Knowledge of modern FP methods

Visited health facilities in the last 12 months

No

Yes

No response

Visited by FP worker in the last 12 months

No

Yes

No response

Told of FP at health facilities in the last 12 months

No

Yes

No response

Exposed to FP messages via mass media in the last few months

No

Yes

Unmet need for spacing

No

Yes

Unmet need for limiting

No

Yes

Total unmet need for FP

No

Yes

Number of women
18.5

28.0

13.8

2.2

I. 4

I. 4

79.2

70.6

84.8

59.9

72.7

69.9

40.0

26.8

29.6

0.1

0.6

0.5

94.0

93.6

88.3

5.9

5.8

II.I

0.1

0.6

0.5

29.0

15.9

16.4

10.9

10.3

12.8

60.1

73.8

70.8

55.9

57.6

64.4

44.1

42.4

35.6

83.7

8I.I

85.4

16.3

18.9

14.6

94.0

94.0

95.5

6.0

6.0

4.5

77.7

75.1

80.9

22.3

24.9

19.1

4448

20936

$\%$ weighted estimate 
African Population Studies Vol. 29, No. I, 2015

Table 3. Prevalence of unmet need for FP disaggregated by the selected characteristics across the years

\begin{tabular}{|c|c|c|c|c|c|c|c|c|c|c|c|c|}
\hline \multirow[b]{3}{*}{ Ar (rom) } & \multicolumn{4}{|c|}{ Unmet need for Spacing } & \multicolumn{4}{|c|}{ Unmet need for Limiting } & \multicolumn{4}{|c|}{ Total unmet need } \\
\hline & Year 2003 & Year 2008 & Year 2013 & & Year 2003 & Year 2008 & Year 2013 & & Year 2003 & Year 2008 & Year 2013 & \\
\hline & $p<0.001$ & $p<0.001$ & $p<0.001$ & & $p<0.001$ & $p<0.001$ & $p<0.001$ & & $p=0.021$ & $p=0.001$ & $p<0.001$ & \\
\hline $15-19$ & 21.2 & 23.7 & 17.3 & $p<0.001$ & 0.5 & 0.5 & 0.0 & $p=0.011$ & 21.7 & 24.2 & 17.4 & $p<0.001$ \\
\hline 20-24 & 18.7 & 22.2 & 16.2 & $p<0.001$ & 0.5 & 0.6 & 0.2 & $p=0.015$ & 19.2 & 22.9 & 16.5 & $p<0.001$ \\
\hline $25-49$ & 14.5 & 17.3 & 13.8 & $p<0.001$ & 8.9 & 8.4 & 6.3 & $p<0.001$ & 23.4 & 25.6 & 20.0 & $p<0.001$ \\
\hline Marital status & $p<0.001$ & $p<0.001$ & $p<0.001$ & & $p=0.001$ & $p<0.001$ & $p<0.001$ & & $p<0.001$ & $p<0.001$ & $p=0.125$ & \\
\hline Never in union & 40.2 & 29.8 & 20.2 & $p<0.001$ & 0.7 & 0.7 & 0.1 & $p=0.040$ & 41.0 & 30.4 & 20.3 & $p<0.001$ \\
\hline Currently in union/cohabiting & 14.6 & 18.2 & 14.3 & $p<0.001$ & 6.3 & 6.3 & 4.7 & $p<0.001$ & 21.0 & 24.5 & 19.0 & $p<0.001$ \\
\hline Formerly in union/cohabiting & 27.5 & 12.0 & 14.4 & $p=0.026$ & 5.9 & 14.6 & 9.4 & $p=0.147$ & 34.6 & 26.1 & 23.9 & $p=0.301$ \\
\hline Educational status & $p<0.001$ & $p<0.001$ & $p<0.001$ & & $p<0.001$ & $p<0.001$ & $p<0.001$ & & $p<0.001$ & $p<0.001$ & $p<0.001$ & \\
\hline No education & 14.3 & 19.9 & 15.0 & $p<0.001$ & 5.3 & 5.0 & 3.4 & $p<0.001$ & 19.5 & 24.9 & 18.4 & $p<0.001$ \\
\hline Primary & 17.7 & 18.3 & 15.1 & $p<0.001$ & 8.7 & 9.2 & 8.0 & $p=0.111$ & 26.5 & 27.5 & 23.1 & $p<0.001$ \\
\hline Secondary & 20.1 & 20.1 & 15.1 & $p<0.001$ & 4.7 & 5.4 & 4.2 & $p=0.006$ & 24.9 & 25.5 & 19.3 & $p<0.001$ \\
\hline Higher & 9.0 & 11.9 & 9.4 & $p=0.025$ & 7.4 & 5.0 & 3.3 & $p=0.001$ & 16.4 & 16.9 & 12.6 & $p=0.001$ \\
\hline Religion & $p=0.005$ & $p<0.001$ & $p=0.346$ & & $p<0.001$ & $p<0.001$ & $p<0.001$ & & $p<0.001$ & $p=0.055$ & $p<0.001$ & \\
\hline Catholic Christians & 17.5 & 15.9 & 14.0 & $p=0.078$ & 10.0 & 9.3 & 6.4 & $p<0.001$ & 27.5 & 25.2 & 20.4 & $p<0.001$ \\
\hline Non catholic Christians & 18.1 & 18.3 & 14.2 & $p<0.001$ & 9.0 & 7.7 & 6.8 & $p=0.006$ & 27.1 & 25.9 & 21.0 & $p<0.001$ \\
\hline Muslims & 15.3 & 20.0 & 15.0 & $p<0.001$ & 3.3 & 4.2 & 2.8 & $p<0.001$ & 18.7 & 24.2 & 17.7 & $p<0.001$ \\
\hline Traditional \& others & 3.4 & 18.4 & 14.0 & $p=0.007$ & 15.3 & 7.0 & 6.1 & $p=0.042$ & 20.0 & 25.3 & 20.1 & $p=0.189$ \\
\hline Currently working & $p=0.039$ & $p<0.001$ & $p<0.001$ & & $p<0.001$ & $p<0.001$ & $p<0.001$ & & $p=0.164$ & $p=0.474$ & $p<0.001$ & \\
\hline No & 17.9 & 21.7 & 15.9 & $p<0.001$ & 2.8 & 3.7 & 2.1 & $p<0.001$ & 20.8 & 25.4 & 18.0 & $p<0.001$ \\
\hline Yes & 15.2 & 17.4 & 13.9 & $p<0.001$ & 7.9 & 7.2 & 5.6 & $p<0.001$ & 23.2 & 24.7 & 19.5 & $p<0.001$ \\
\hline No response & 25.0 & 19.3 & 29.5 & $p=0.173$ & 0.0 & 4.4 & 2.7 & $p=0.594$ & 25.0 & 23.7 & 31.9 & $p=0.351$ \\
\hline $\begin{array}{l}\text { Decision-making on spending } \\
\text { personal earnings }\end{array}$ & $p=0.013$ & $p<0.001$ & $p<0.001$ & & $p<0.001$ & $p<0.001$ & $p<0.001$ & & $p=0.836$ & $p=0.001$ & $p=0.392$ & \\
\hline Not autonomous & 14.0 & 15.6 & 12.3 & $p<0.001$ & 7.6 & 7.0 & 6.7 & $p=0.592$ & 21.7 & 22.6 & 19.0 & $p<0.001$ \\
\hline Autonomous & 15.2 & 18.5 & 14.2 & $p<0.001$ & 7.5 & 6.7 & 5.2 & $p<0.001$ & 22.7 & 25.2 & 19.4 & $p<0.001$ \\
\hline No response & 18.0 & 20.4 & 16.1 & $p<0.001$ & 4.1 & 5.2 & 2.6 & $p<0.001$ & 22.1 & 25.6 & 18.7 & $p<0.001$ \\
\hline Type of household & $p=0.063$ & $p=0.005$ & $p=0.068$ & & $p=0.055$ & $p<0.001$ & $p<0.001$ & & $p=0.753$ & $p<0.001$ & $p<0.001$ & \\
\hline Male-headed & 15.9 & 18.6 & 14.5 & $p<0.001$ & 5.8 & 5.8 & 4.2 & $p<0.001$ & 21.7 & 24.5 & 17.0 & $p<0.001$ \\
\hline Female-headed & 19.3 & 21.0 & 15.8 & $p<0.001$ & 8.0 & 7.6 & 6.4 & $p=0.155$ & 27.3 & 28.6 & 20.3 & $p<0.001$ \\
\hline Household wealth status & $p=0.198$ & $p<0.001$ & $p<0.001$ & & $p=0.074$ & $p<0.001$ & $p<0.001$ & & $p=0.243$ & $p<0.001$ & $p<0.001$ & \\
\hline Poor & 15.6 & 19.5 & 15.1 & $p<0.001$ & 5.5 & 4.9 & 3.3 & $p<0.001$ & 21.0 & 24.4 & 18.4 & $p<0.001$ \\
\hline Average & 18.2 & 20.6 & 17.8 & $p=0.005$ & 5.2 & 7.5 & 5.7 & $p=0.002$ & 23.3 & 28.0 & 23.6 & $p<0.001$ \\
\hline Rich & 16.0 & 17.6 & 12.7 & $p<0.001$ & 7.0 & 6.5 & 5.1 & $p<0.001$ & 23.0 & 24.1 & 17.8 & $p<0.001$ \\
\hline $\begin{array}{l}\text { Number of living children } \\
\text { (including current pregnancy) }\end{array}$ & $p<0.001$ & $p<0.001$ & $p=0.001$ & & $p<0.001$ & $p<0.001$ & $p<0.001$ & & $p<0.001$ & $p<0.001$ & $p<0.001$ & \\
\hline $0-1$ & 19.8 & 21.1 & 15.0 & $p<0.001$ & 0.3 & 0.6 & 0.0 & $p<0.001$ & 20.1 & 21.6 & 15.0 & $p<0.001$ \\
\hline 2 & 13.8 & 19.4 & 16.4 & $p<0.001$ & 1.0 & 1.1 & 0.7 & $p=0.109$ & 14.8 & 20.5 & 17.1 & $p<0.001$ \\
\hline$\geq 3$ & 15.0 & 17.7 & 13.9 & $p<0.001$ & 10.8 & 10.2 & 7.6 & $p<0.001$ & 25.8 & 27.9 & 21.5 & $p<0.001$ \\
\hline Residence & $p=0.609$ & $p<0.001$ & $p<0.001$ & & $p=0.787$ & $p=0.394$ & $p=0.161$ & & $p=0.753$ & $p<0.001$ & $p<0.001$ & \\
\hline Urban & 15.9 & 16.7 & 12.3 & $p<0.001$ & 6.1 & 6.2 & 4.7 & $p<0.001$ & 22.0 & 22.9 & 17.0 & $p<0.001$ \\
\hline $\begin{array}{l}\text { Rural } \\
\text { Region }\end{array}$ & $\begin{array}{l}16.5 \\
p=0.561\end{array}$ & $\begin{array}{l}20.0 \\
p=0.001\end{array}$ & $\begin{array}{l}16.0 \\
p<0.001\end{array}$ & $p<0.001$ & $\begin{array}{l}5.9 \\
p<0.001\end{array}$ & $\begin{array}{l}5.9 \\
p<0.001\end{array}$ & $\begin{array}{l}4.3 \\
p<0.001\end{array}$ & $p<0.001$ & $\begin{array}{l}22.4 \\
p<0.001\end{array}$ & $\begin{array}{l}26.0 \\
p=0.066\end{array}$ & $\begin{array}{l}20.3 \\
p=0.506\end{array}$ & $p<0.001$ \\
\hline Northern & 16.0 & 19.7 & 15.8 & $p<0.001$ & 4.3 & 4.7 & 3.4 & $p<0.001$ & 20.3 & 24.5 & 19.2 & $p<0.001$ \\
\hline $\begin{array}{l}\text { Southern } \\
\text { Knowledge of modern FP } \\
\text { method }\end{array}$ & $\begin{array}{l}16.7 \\
p=0.478\end{array}$ & $\begin{array}{l}17.9 \\
p<0.001\end{array}$ & $\begin{array}{l}12.5 \\
p<0.001\end{array}$ & $p<0.001$ & $\begin{array}{l}9.3 \\
p=0.017\end{array}$ & $\begin{array}{l}7.7 \\
p<0.001\end{array}$ & $\begin{array}{l}6.3 \\
p<0.001\end{array}$ & $p<0.001$ & $\begin{array}{l}26.1 \\
p=0.037\end{array}$ & $\begin{array}{l}25.6 \\
p=0.464\end{array}$ & $\begin{array}{l}18.8 \\
p=0.001\end{array}$ & $p<0.001$ \\
\hline
\end{tabular}




\begin{tabular}{|c|c|c|c|c|c|c|c|c|c|c|c|c|}
\hline No knowledge & 14.9 & 21.1 & 18.3 & $p<0.001$ & 4.1 & 3.3 & 2.0 & $p<0.001$ & 19.0 & 24.4 & 20.3 & $p<0.001$ \\
\hline Knowledge of folkloric/traditional & 17.5 & 21.1 & 8.5 & $p<0.001$ & 3.9 & 5.2 & 3.8 & $p=0.670$ & 22.1 & 26.0 & 12.3 & $p<0.001$ \\
\hline Knowledge of modern methods & 16.6 & 18.0 & 14.1 & $p<0.001$ & 6.5 & 7.1 & 4.9 & $p<0.001$ & 23.0 & 25.1 & 19.0 & $p<0.001$ \\
\hline $\begin{array}{l}\text { Visited by FP worker in the last } \\
12 \text { months }\end{array}$ & $p=0.077$ & $p=0.021$ & $p<0.001$ & & $p=0.084$ & $p=0.013$ & $p=0.926$ & & $p=0.600$ & $p=0.513$ & $p<0.001$ & \\
\hline No & 16.5 & 19.1 & 15.0 & $p<0.001$ & 5.9 & 5.9 & 4.5 & $p<0.001$ & 22.4 & 25.0 & 19.5 & $p<0.001$ \\
\hline Yes & 12.5 & 16.4 & 11.2 & $p<0.001$ & 8.4 & 7.7 & 4.5 & $p<0.001$ & 20.9 & 24.1 & 15.7 & $p<0.001$ \\
\hline $\begin{array}{l}\text { Visited health facilities in the } \\
\text { last } 12 \text { months }\end{array}$ & $p=0.205$ & $p=0.001$ & $p<0.001$ & & $p=0.141$ & $p=0.096$ & $p=0.497$ & & $p=0.801$ & $p<0.001$ & $p<0.001$ & \\
\hline No & 16.8 & 19.5 & 15.3 & $p<0.001$ & 5.6 & 6.2 & 4.5 & $p<0.001$ & 22.4 & 25.7 & 19.8 & $p<0.001$ \\
\hline Yes & 15.4 & 17.3 & 12.9 & $p<0.001$ & 6.6 & 5.6 & 4.3 & $p<0.001$ & 22.1 & 22.9 & 17.2 & $p<0.001$ \\
\hline Told of FP at health & $p=0.40 I$ & $p=0.001$ & $p<0.001$ & & $p=0.015$ & $p=0.203$ & $p=0.28 I$ & & $p=0.098$ & $p<0.001$ & $p<0.001$ & \\
\hline No & 15.1 & 17.6 & 13.4 & $p<0.001$ & 5.7 & 5.5 & 4.6 & $p=0.167$ & 20.8 & 23.1 & 18.1 & $p<0.001$ \\
\hline Yes & 16.4 & 16.8 & 12.1 & $p<0.001$ & 8.9 & 5.7 & 3.9 & $p<0.001$ & 25.4 & 22.5 & 16.0 & $p<0.001$ \\
\hline No response & 16.8 & 19.5 & 15.3 & $p<0.001$ & 5.6 & 6.2 & 4.5 & $p<0.001$ & 22.4 & 25.7 & 19.9 & $p<0.001$ \\
\hline $\begin{array}{l}\text { Exposed to FP messages via } \\
\text { mass media in the last few } \\
\text { months }\end{array}$ & $p=0.728$ & $p<0.001$ & $p<0.001$ & & $p=0.200$ & $p=0.008$ & $p=0.001$ & & $p=0.676$ & $p=0.002$ & $p<0.001$ & \\
\hline No & 16.4 & 20.1 & 15.9 & $p<0.001$ & 5.6 & 5.6 & 4.1 & $p<0.001$ & 22.1 & 25.7 & 20.0 & $p<0.001$ \\
\hline Yes & 16.1 & 17.3 & 12.3 & $p<0.001$ & 6.5 & 6.5 & 5.0 & $p<0.001$ & 22.6 & 23.9 & 17.3 & $p<0.001$ \\
\hline
\end{tabular}


Table 4. Multivariable models for determinants of unmet need for FP among currently married and sexually active unmarried women

\begin{tabular}{|c|c|c|c|}
\hline \multirow[t]{2}{*}{ Variables } & $\begin{array}{lll}\text { Unmet need for } \\
\text { Spacing }\end{array}$ & $\begin{array}{lll}\begin{array}{l}\text { Unmet } \\
\text { Limiting }\end{array} & \text { need } & \text { for } \\
\end{array}$ & \multirow{2}{*}{$\begin{array}{l}\text { Total Unmet need for } \\
\text { FP } \\
\text { Adjusted PR }(95 \% \mathrm{Cl}) \\
\end{array}$} \\
\hline & \multicolumn{2}{|l|}{ Adjusted PR (95\%Cl) } & \\
\hline \multicolumn{4}{|l|}{ Year } \\
\hline 2003 & 1.00 & 1.00 & 1.00 \\
\hline 2008 & $1.16(1.08,1.25)$ & $0.89(0.79,1.01)$ & $1.09(1.03,1.15)$ \\
\hline 2013 & $0.92(0.85,0.99)$ & $0.7 \mathrm{I}(0.62,0.80)$ & $0.85(0.8 I, 0.9 I)$ \\
\hline \multicolumn{4}{|l|}{ Age } \\
\hline $15-19$ & 1.00 & 1.00 & 1.00 \\
\hline $20-24$ & $0.96(0.90,1.03)$ & $0.39(0.21,0.72)$ & $0.85(0.79,0.91)$ \\
\hline $25-49$ & $0.86(0.80,0.93)$ & $2.03(1.17,3.55)$ & $0.85(0.79,0.92)$ \\
\hline \multicolumn{4}{|l|}{ Marital status } \\
\hline Never in union & 1.00 & 1.00 & 1.00 \\
\hline $\begin{array}{l}\text { Currently in } \\
\text { union/cohabiting }\end{array}$ & $0.53(0.49,0.58)$ & $\mathrm{I} .39(0.75,2.57)$ & $0.64(0.59,0.69)$ \\
\hline $\begin{array}{l}\text { Formerly in } \\
\text { union/cohabiting } \\
\text { Educational status }\end{array}$ & $0.56(0.44,0.72)$ & I.34(0.69, 2.62) & $0.69(0.57,0.82)$ \\
\hline No education & 1.00 & 1.00 & 1.00 \\
\hline Primary & $1.1 \mathrm{I}(1.05,1.18)$ & $1.02(0.92,1.13)$ & $1.09(1.03,1.14)$ \\
\hline Secondary & $1.16(1.08,1.24)$ & $0.75(0.66,0.85)$ & $1.00(0.94,1.06)$ \\
\hline Higher & $0.74(0.66,0.83)$ & $0.70(0.58,0.84)$ & $0.70(0.64,0.77)$ \\
\hline \multicolumn{4}{|l|}{ Religion } \\
\hline Catholic Christians & 1.00 & 1.00 & 1.00 \\
\hline \multicolumn{4}{|l|}{ Christians } \\
\hline Muslims & $1.03(0.95,1.12)$ & $0.44(0.38,0.50)$ & $0.82(0.77,0.88)$ \\
\hline $\begin{array}{l}\text { Traditional \& others } \\
\text { Currently working }\end{array}$ & $0.96(0.80,1.14)$ & $0.74(0.57,0.95)$ & $0.88(0.77,1.01)$ \\
\hline No & 1.00 & 1.00 & 1.00 \\
\hline Yes & $0.84(0.79,0.90)$ & $1.31(1.15,1.48)$ & $0.93(0.89,0.98)$ \\
\hline No response & $1.19(0.95,1.49)$ & $1.00(0.53,1.90)$ & $\mathrm{I} .15(0.93, \mathrm{I} .4 \mathrm{I})$ \\
\hline \multicolumn{4}{|l|}{$\begin{array}{l}\text { Decision-making on } \\
\text { spending personal } \\
\text { earnings }\end{array}$} \\
\hline Not autonomous & 1.00 & 1.00 & 1.00 \\
\hline Autonomous & $1.13(1.06,1.21)$ & $1.08(0.98,1.18)$ & $1.10(1.05,1.16)$ \\
\hline No response & $0.98(0.91,1.06)$ & $1.17(1.04,1.32)$ & $1.02(0.96,1.09)$ \\
\hline \multicolumn{4}{|l|}{ Type of household } \\
\hline Male-headed & 1.00 & 1.00 & 1.00 \\
\hline $\begin{array}{l}\text { Female-headed } \\
\text { Household wealth } \\
\text { status }\end{array}$ & $1.06(1.00,1.13)$ & $1.36(1.22,1.5 \mathrm{I})$ & $1.13(1.07,1.19)$ \\
\hline Poor & 1.00 & 1.00 & 1.00 \\
\hline Average & $1.18(1.12,1.25)$ & $1.29(1.16,1.43)$ & $1.20(1.14,1.25)$ \\
\hline Rich & $1.09(1.02,1.16)$ & $1.35(1.20,1.52)$ & $1.14(1.08,1.21)$ \\
\hline $\begin{array}{l}\text { Number of living } \\
\text { children } \\
\text { current pregnancy) }\end{array}$ & & & \\
\hline $0-1$ & 1.00 & 1.00 & 1.00 \\
\hline 2 & $1.16(1.09,1.25)$ & $2.62(1.71,4.00)$ & $1.19(1.11,1.27)$ \\
\hline$\geq 3$ & $1.10(1.03,1.18)$ & $18.40(12.66,26.73)$ & $1.59(1.50,1.69)$ \\
\hline Residence & & & \\
\hline Urban & 1.00 & 1.00 & 1.00 \\
\hline
\end{tabular}




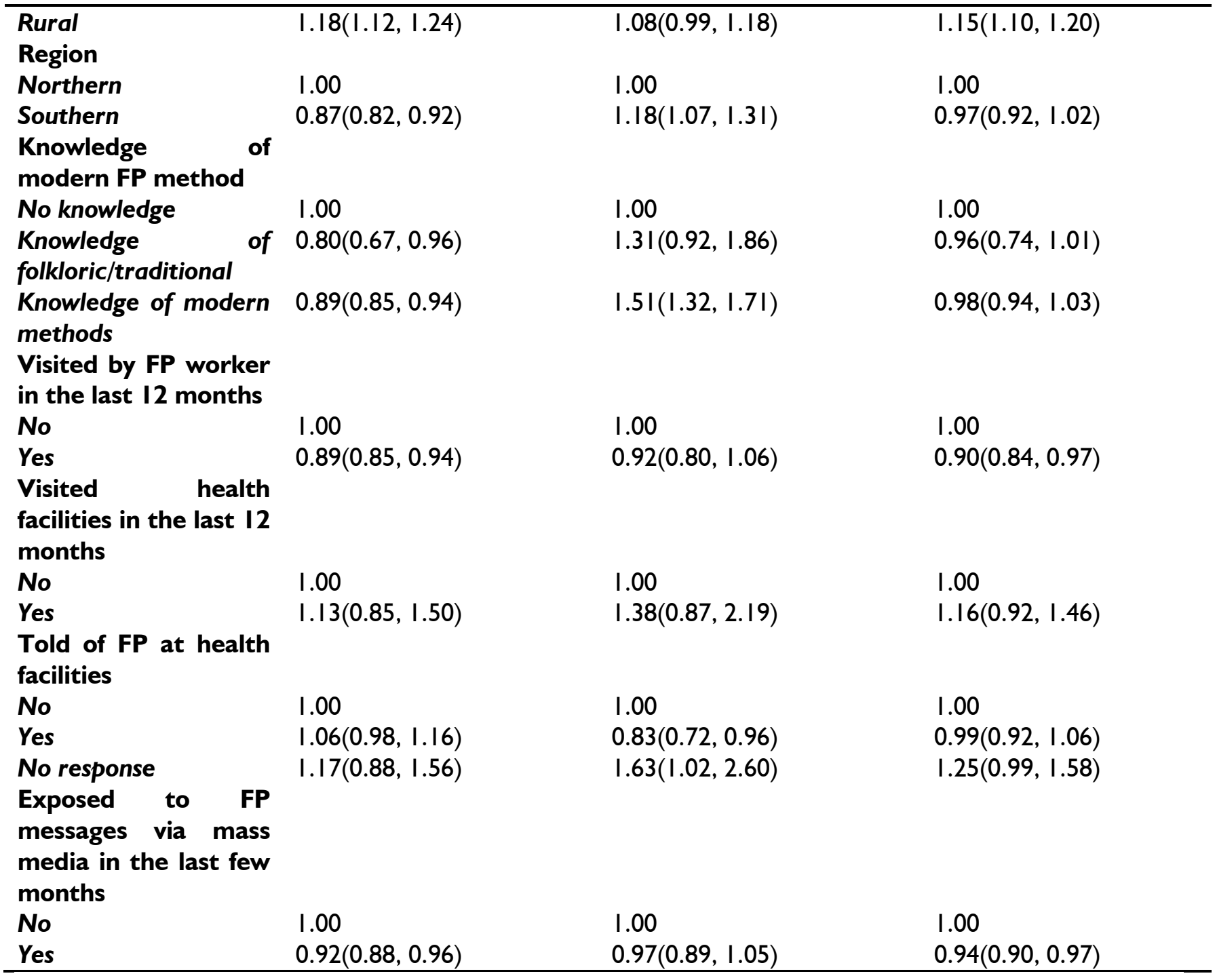

Factors associated with unmet need for spacing

In Table 3, respondent's age, marital status, educational status, current work status, decisionmaking on spending personal earning and number of living children (including pregnancy) were consistently associated $(p<0.05)$ with unmet need for spacing through the three rounds of the survey. Unmet need for spacing also changed significantly $(p<0.05)$ across the years for almost all sub-groups of respondents with exception of those who were Catholic Christians.

In the multivariable model (Table 4), unmet need for spacing was $16 \%$ higher in 2008 compared with 2003. After controlling for the influence of the survey years, the model shows that women aged 25-49 were less likely to have unmet need for spacing compared to those aged 15-19; and those currently married and formerly married were less likely to have unmet need for spacing than those never married. Furthermore, those currently working were less likely to have unmet need for spacing than those not currently working; those resident in Southern Nigeria were also less likely to have unmet need for spacing than those in the Northern region; those with knowledge of FP (Folkloric/traditional or modern methods) were less likely to have unmet need for spacing than those with no knowledge of FP; those visited by FP worker(s) in the last 12 months were also less likely to have unmet need for spacing than those not visited; and those exposed to FP messages via mass media in the last few months were less likely to have unmet need for spacing than those not exposed.

The model also shows that those with primary and secondary education respectively were more likely to have unmet need for spacing than those with no formal education; those who had autonomy to take decision on spending personal earnings were more likely to have unmet need for spacing than those with no autonomy; those from average and rich households respectively were more likely to have unmet need for spacing than those from poor households; those having two or more children were more likely to have unmet need for spacing than those with one or no child; and the rural dwellers were more likely to have unmet need for spacing than the urban dwellers. 


\section{Factors associated with unmet need for limiting}

Similar to spacing, age, marital status, educational status, religion, current work status, decision-making on spending personal earning, number of living children (including pregnancy), region and knowledge of modern FP were identified as factors consistently associated with unmet need for limiting in each of the years under review. Unmet need for limiting also changed significantly across the years in some subgroups of the study population, with exception of women who were formerly married/cohabiting; women with primary school education; women with no autonomous decision-making on spending personal earning; women in female headed households; women with two living children (including pregnancy); women with knowledge of folkloric/traditional FP methods only; and women who were never told of $\mathrm{FP}$ at health facilities.

In the multivariable model in Table 4, unlike 2008 estimate, the estimate of unmet need for limiting in 2013 was lower than it was in 2003. After controlling for the influence of the survey years, the model shows that women aged 20-24 were less likely to have unmet need for limiting compared to those aged 15-19; those with secondary and higher education respectively were less likely to have unmet need for limiting than those with no formal education; all those who were non-Catholic Christians were less likely to have unmet need for limiting than the Catholic Christians; and those who were told about FP at health facilities were less likely to have unmet need for limiting than those who were never told.

The multivariable model also shows that those currently working among the women were more likely to have unmet need for limiting than those not currently working; those residing in female-headed households were also more likely to have unmet need for limiting than those in male-headed households; those from average and rich households were more likely to have unmet need for limiting than those from poor households; those having two or more children were more likely to have unmet need for limiting than those with one or no child; those in Southern Nigeria were also more likely to have unmet need for limiting than those in the Northern region; and those with knowledge of modern FP were more likely to have unmet need for limiting than those with no knowledge of FP.

Factors associated with total unmet need for FP

Quite a few independent variables consistently showed significant associations with total unmet need for FP in each of the three years under review. The identified variables in the bivariable analysis included respondents' age, educational status and number of living children (including pregnancies). In almost all the subgroups of the study population, total unmet need for FP changed significantly $(p<0.05)$ across the years except among women who were formerly married/cohabiting; and women with traditional religion or religion other than Christianity and Islam

However in the multivariable model contained in Table 4, total unmet need for FP among the women in 2008 was slightly higher than the estimate in 2003, but lower than the estimate in 2013. After controlling for influence of the survey years, the model for total unmet need for FP shows that both women of ages 20-24 and 25-49 respectively were less likely to have unmet need for FP than those aged 15-19; both currently married/cohabiting women and those formerly married were also less likely to have unmet need for FP than those who were never married; and those with higher education were also less likely to have total unmet need for FP than those with no formal education. In addition, only female Muslims were less likely to have unmet need for FP than the Catholic-Christians; those currently working were also less likely to have unmet need for FP for spacing and limiting than those not currently working; those visited by FP worker(s) in the last 12 months were less likely to have unmet need for FP overall than those not visited; and those exposed to FP messages via mass media in the last few months were less likely to have total unmet need for FP than those not exposed.

On the other hand, those with primary education among the women were more likely to have unmet need for FP than those without formal education. Similarly, those with autonomy to take decisions on spending personal earnings were more likely overall to have unmet need for FP than those with no autonomy; women from female-headed households were more likely overall to have unmet need for FP (for spacing and limiting) than those from maleheaded households; those from average and rich households respectively were more likely than those from poor households; and the rural dwellers among the women were more likely than their counterparts in the urban areas.

\section{Discussion}

This study examined trends in prevalence and determinants of unmet need for FP services among currently married and sexually active unmarried women of reproductive age (15-49) in Nigeria over a decade (2003-20I3). Overall, trend in unmet need for FP (spacing, limiting and total) has declined significantly over the 10-year period. The significant increase in unmet need for spacing and total unmet need for FP observed between 2003 and 2008 aligns with the global trend where the number of women wanting to avoid pregnancy and therefore needing effective contraception substantially increased from 716 million (54\%) of 1321 million in 2003 , to 827 
million (57\%) of I 448 million in 2008, to 867 million (57\%) of 1520 million in 2012 (Darroch and Singh, 2013). However, this increase was short-lived.

Evidence from existing literature (Darroch and Singh, 2013, Sharan et al., 2011, Mills et al., 2010, Ezeh et al., 2009) suggests that changes in levels of unmet need for FP have a number of implications related to population growth, fertility transition, demand and supply of FP, and wealth status. As there is an indication that population growth is critical to triggering unmet needs of FP (Darroch and Singh, 2013), the slight increase in unmet need for FP in Nigeria between 2003 and 2008 could have been triggered by the explosive increase in the country's population from 88.6 million in 199 I to 140.4 million in 2006 with a national growth rate estimate of $3.2 \%$, thereby making the country by far the most populous nation in Africa (National Population Commission [NPC] and ICF Macro, 2009). Similar to evidence from some Eastern African countries like Kenya, Uganda, Zimbabwe and Tanzania indicating that increases in unmet need for FP were consistently associated with halts in fertility decline (Ezeh et al., 2009), perhaps in Nigeria, there were halts in fertility decline between 2003 and 2008, which could be responsible for the slight increase in unmet need for FP within the period in the country.

Unmet need for FP is often considered a precursor of fertility decline, indicating that demand for FP services exists but is not being met (Sharan et al., 20II). However, the relationship between fertility transition and trends in unmet need for FP calls for careful interpretation as different levels of unmet need and total potential demand for FP in SubSaharan African countries were found to reflect a non-linear pattern of unmet need over the fertility transition (Mills et al., 20l0). Another evidence from Kenya, Madagascar, Malawi, and Zambia, shows that decline in unmet need for FP could correspond with an increase in FP use, suggesting a convergence of demand and supply of FP (Sharan et al., 20II). This could also be true for Nigeria, because as unmet need for FP in the country declined from $15.6 \%$ in 2008 to $12.7 \%$ in 2013 , while contraceptive prevalence increased simultaneously from $14.6 \%$ in 2008 (National Population Commission [NPC] and ICF Macro, 2009) to $16 \%$ in 2013 (National Population Commission (NPC) [Nigeria] and ICF International, 20/4); thus suggesting a situation of convergence between demand and supply of FP in Nigeria. It is also believed that in a few African countries (including Nigeria) where unmet need was found to increase with wealth, such countries are in the earlier stages of declining desired family size, which declines first in urban areas, among the more educated women, and among wealthier households (Mills et al., 2010). It is likely that this trend will increase demand for contraceptives, which unfortunately current FP programs and providers will initially not be able to meet, although over time, this pattern will be reversed (Mills et al., 2010).

In this study, a number of factors have been identified as determinants of unmet need for spacing, limiting or total unmet need for FP. Prominent among the determinants of unmet need of FP was age (Hailemariam and Haddis, 20II, Ojakaa, 2008). In contrast to other studies (Hameed et al., 20II, Klijzing, 2000) which found unmet need for FP increasing with age, this study demonstrated the reverse with older adult (aged 25-49) and young adult women (20-24) less likely to have total unmet need for FP compared to those aged 15-19. Specifically, the older adult women (aged 25-49) were found less likely to have unmet need for spacing but more likely to have unmet need for limiting, than the adolescent women (aged 15-19); while the young adult women (aged 20-24) were only less likely to have unmet need for limiting than the adolescent women (aged 15-19). These findings support the claim that young people are among the groups most likely to have unmet need for FP (Ojakaa, 2008) because they are sexually active, and more desirous of avoiding pregnancy, but are not using modern methods of contraception (United Nations, 20II). Ironically, although the main reason for FP demand among young women is spacing (Jansen, 2005), adolescent women have lower use of contraception, poorer knowledge of FP and less access to information and services than adult women (Al-Jawadi and Al-Bakry, 2010, Kennedy et al., 20II). These factors might actually be responsible for why adult women are less likely to have unmet need for FP than adolescent women in Nigeria.

With respect to marital status, the present study found currently married women and formerly married women less likely to have unmet need for spacing and total unmet need for FP compared to never married women. Although this pattern is not quite clear; it contradicts the notion that currently married women might comprise both women who have a greater need for FP for spacing (or delaying) births in the early years of marriage and those whose need has shifted to limiting births because they have achieved their desired number of children (RoudiFahimi et al., 20I2). In Hungary, a study showed that unmet need was higher among those in marital unions than among those in less formal relationships (Klijzing, 2000). Opposition from husbands or partners (Khan Shane et al., 2008, Westoff, 2012) could also make currently married/cohabiting women more likely to have higher unmet need for FP than the never married women. On the other hand, studies have shown that available data on unmet need for FP might understate the true demand for FP 
among unmarried women (Kols, 2008). Unmarried women are often excluded in studies, because it is difficult to collect reliable information from them (Casterline and Sinding, 2000, Westoff, 2006) as unmarried young people face great barriers to services and may have higher levels of unmet need for FP than married women (Bernstein and Edouard, 2007). Furthermore, the needs of formerly married women may have shifted to limiting births because they might have had their desired number of children with their former spouses.

There is no gainsaying that educational level plays an important role in shaping unmet need for FP (Hailemariam and Haddis, 20II, Acacio-Claro and Borja, 2010, Ali and Okud, 2013, Ojakaa, 2008). In this study, women with higher education were found to be less likely to have unmet need for spacing, limiting and total unmet need for FP as observed in Eastern Sudan (Ali and Okud, 2013). While women with unmet need for both spacing and limiting in Ethiopia were found more likely to have lower levels of education (Hailemariam and Haddis, 20I I), this present study found that women with primary and secondary education were more likely to have unmet need for spacing. Therefore, this study supports the fact that generally in SSA, most of the declines in unmet need are among women with at least primary school level education (Westoff, 2006).

Also in this study, religion was significantly associated with unmet need for limiting. Although the reason for this pattern is unclear, perhaps it has to do with the position of the Catholic Church to modern contraception (Westoff, 20I2).

With regard to occupation, this study supports the findings from studies in Ethiopia (Hailemariam and Haddis, 20II), Kenya(Ojakaa, 2008) and Eastern Sudan (Ali and Okud, 2013) which showed that total unmet need decreases with women's employment. For instance, women in this study, who were currently working were less likely to have unmet need for spacing and total unmet need for FP, but more likely to have unmet need for limiting. In this study, women from average and rich households were more likely to have unmet need for spacing, limiting and total unmet need than those from poor households. This contradicts the notion that in a given country, the poor may tend to experience higher levels of unmet need for FP as their desire to limit or space births increases, while wealthier groups experience diminishing unmet need due to increased FP use (Health Policy Initiative Task Order I Constella Futures, 2007). Nigeria is among the few countries (like Benin, Chad and Mali) with women in the wealthiest quintile displaying higher unmet needs than the women in lower quintiles, whereas in other countries such as Bolivia, Ghana, Togo, and Zimbabwe, the patterns are reversed (Mills et al.,
2010). According Mills et al., the reasons are essentially the same as for differences among countries at different stages of fertility decline; because countries in which unmet need increases with increasing wealth tend to be in the earlier stages of declining desired family size, which declines first in urban areas, among more educated women, and among wealthier households. As FP programs and other providers are unable to meet the increased demand for contraceptives or address concerns about health and side effects, unmet need increases in the wealthier quintiles, while it remains low in the poorest quintiles where demand for FP remains low.

This study also found unmet need for FP to be higher among women with higher number of living children than among women with one or no child or pregnancy. This confirms findings from previous studies (Hameed et al., 20II, Khan Shane et al., 2008, lgwegbe et al., 2009). The higher likelihood of unmet need for FP among women with higher number of living children (including current pregnancy) therefore suggests more of unmet need for limiting than for spacing births (Klijzing, 2000).

Regional differentials were observed in this study as women in the Southern region of the country were less likely to have unmet need for spacing but more likely to have unmet need for limiting than their counterparts in the Northern region of Nigeria.

Interestingly, women with knowledge of FP (folkloric/traditional or modern methods) in this study were less likely to have unmet need for spacing than those with no knowledge of FP; whereas, those with knowledge of modern FP were more likely to have unmet need for limiting than those with no knowledge of FP.

Further, although findings from studies in SSA may be conflicting on the association between exposure to FP-related messages and unmet need (Hailemariam and Haddis, 20II, Ojakaa, 2008, National Population Commission [NPC] and ICF Macro, 2009, Dutta Arin and Charles Hongoro, 20I3), in this study, women who were visited by FP worker(s) in the last 12 months and those were exposed to mass media in the last 12 months were less likely to have total unmet need for FP than those who did not.

Generally, public health and economic significance of the burden of unmet need demonstrated by findings this study can be generalized to the large size of women represented by women in this study female adolescents; never married women; women not currently working; women in female-headed households; women in rich households; women with high parity; women in rural areas; women who have not been visited by FP workers; and women who are not exposed to FP messages via mass media). According to Nigeria's 2006 Population and Housing 
Census, women of reproductive age (15-49) accounted for about one-quarter $(\approx 35.0$ million) of the entire country's population of 140 million; and about $21 \%(\approx 7.4$ million $)$ and $34 \%(\approx 12.0$ million $)$ of the women of reproductive age were female adolescents and never married women respectively. Therefore, the large population of women who are more likely to have unmet need for FP in Nigeria in the context of the attendant consequences of unmet need for FP calls for urgency in increasing and improving FP supply to bridge this gap in FP demands.

\section{Conclusion}

In conclusion, although unmet need for FP among currently married women and sexually active unmarried women of reproductive age in Nigeria has significantly declined in the last decade. Against the International Conference on Population and Development (ICPD) benchmark of zero unmet need by 2014, the current level of unmet need for FP among women is still far below expectation. Meeting the ICPD benchmark requires the concerted efforts by government, public and private sector to urgently expand FP services to female adolescents, unmarried women and women with many living children. .

\section{Acknowledgement}

Our sincere appreciation goes to the ORC Macro International and the National Population Commission, Abuja, Nigeria for the datasets.

\section{References}

Acacio-Claro, P. J. B. \& Borja, M. P. 2010. Addressing Unmet Need: Potential for Increasing Contraceptive Prevalence in the Philippines. AsiaPacific Population Journal, 25.

Adesina, D. 2009. The National Health Insurance Scheme [Online]. TheNigerianDoctor.org Available:

http://thenigeriandoctor.org/news.php?extend.850 [Accessed 04/06/20I4 20I4].

Adhikari, R. \& Podhisita, C. 2010. Household headship and Child death: Evidence from Nepal. BMC International Health and Human Rights, 10.

Al-jawadi, A. A. \& Al-Bakry, D. H. 20I0. Family Planning Unmet Need Profile in Monsul City, North of Iraq: a Cross-Sectional Study Duhok Med J, 4, 40-50.

Ali, A. A. A. \& Okud, A. 2013. Factors affecting unmet need for family planning in Eastern Sudan. BMC Public Health, 13, I-5.

Arshad, M. J. \& Masood, I. 20I0. Family Advancement for Life and Health (FALAH), Upper Dir Baseline Household Survey.
Bernstein, S. \& Edouard, L. 2007. Targeting access to reproductive health: giving contraception more prominence and using indicators to monitor progress. Reproductive Health Matters, 15, 186191.

Bongaarts, J., Cleland, J., Townsend, J. W., Bertrand, J. T. \& Gupta, M. d. 2012. Family Planning Programs for the 2 Ist Century : Rationale and Design. New York: The Population Council.

Casterline, J. \& Sinding, S. 2000. Unmet need for family planning in developing countries and implications for population policy. Population and Development Review, 26, 691-723.

Cleland, J., Bernstein, S., Ezeh, A., Faundes, A., Glasier, A. \& Innis, J. 2006. Family planning: the Unfinished Agenda. Lancet, 368.

Darroch, J. E. \& Singh, S. 2013. Trends in contraceptive need and use in developing countries in 2003, 2008, and 2012: an analysis of national surveys. Lancet, $38 \mathrm{I}$.

Dutta Arin \& Charles Hongoro 2013. Scaling Up National Health Insurance in Nigeria: Learning from Case Studies of India, Colombia, and Thailand. Washington, DC: Futures Group, Health Policy Project.

Dyson, T. \& Moore, M. 1983. On kinship structure, female autonomy, and demographic behavior in India. Population and Development Review, 9, 3560.

Ezeh, A. C., Mberu, B. U. \& Emina, J. O. 2009. Stall in fertility decline in Eastern African countries: regional analysis of patterns, determinants and implications. Phil. Trans. R. Soc. B, 364, 299I-3007.

Gardella, A. 2006. Gender Assessment for USAID/HAITI Country Strategy Statement USAID.

Hailemariam, A. \& Haddis, F. 20I I. Factors affecting Unmet need for Family planning in Southern Nations, Nationalities and Peoples Region, Ethiopia. Ethiop J Health Sci., 2I.

Hameed, W., Azmat, S. K., Bilgrami, M. \& Ishaqe, M. 20II. Determining the factors associated with Unmet need for family planning : A cross-sectional survey in 49 districts of Pakistan. PJPH, I, 2I-27.

Health Policy Initiative Task Order I Constella Futures 2007. Inequalities in Use of Family Planning and Reproductive Health Services: Implications for Policies and Programs. Washington, DC 20005 USA: USAID.

Igwegbe, A., Ugboaja, J. \& Monago, E. 2009. Prevalence and determinants of unmet need for family planning in Nnewi, south-east Nigeria. Int. J. Med. Med. Sci., I, 325-329.

Jansen, W. 2005. Existing Demand for Birth Spacing in Developing Countries: Perspectives from Household Survey Data. . International Journal of Obstetrics and Gynecology, 89. 
Kennedy, E., Gray, N., Azzopardi, P. \& Creati, M. 201I. Adolescent fertility and family planning in East Asia and the Pacific: a review of DHS reports. Reproductive Health, 8.

Khan Shane, Sarah E.K. Bradley, Joy Fishel \& Vinod Mishra 2008. Unmet Need and the Demand for Family Planning in Uganda: Further Analysis of the Uganda Demographic and Health Surveys, 19952006. . Calverton, Maryland, USA: Macro International Inc.

Klijzing, E. 2000. Are There Unmet Family Planning Needs in Europe? Family Planning Perspectives, 32, $74-81$ \& 88.

Kols, A. 2008. Reducing unmet need for family planning: Evidence-based strategies and approaches. Outlook 25th Anniversary Issue [Online], 25.

Maitra, P. 2004. Parental bargaining, health inputs and child mortality in India. Journal of Health Economics, 23, 259-29l.

Mills, S., Bos, E. \& Suzuki, E. 2010. Unmet need for contraception: At a glance. Human Development Network at the World Bank.

Moreland, S. \& Talbird, S. 2006. Achieving the Millennium Development Goals: The contribution of fulfilling the unmet need for family planning. USAID.

National Population Commission (NPC) [Nigeria] \& and ORC Macro 2003. Nigeria Demographic and Health Survey. Abuja.

National Population Commission (NPC) [Nigeria] and ICF International 20I4. Nigeria Demographic and Health Survey 2013. Abuja, Nigeria and Rockville, Maryland, USA: NPC and ICF International.

National Population Commission [Nigeria] 2000. Nigeria Demographic and Health Survey 1999. Calverton Maryland: National Population Commission and ORC/Macro.

National Population Commission [NPC] and ICF Macro 2009. Nigeria Demographic and Health Survey 2008. National Population Commission and ICF Macro.

Ojakaa, D. 2008. Trends and Determinants of Unmet Need for Family Planning in Kenya. DHS Working Papers. Macro International Inc.

Pallikadavath, S. \& Stones, R. 2006. Maternal and Social Factors Associated with Abortion in India: A Population-Based Study. International Family Planning Perspectives, 32, I20-I 25.

Population and Sustainability Network [PSN] 2012. Population Dynamics and Biodiversity. A PSN Briefing Paper
Prata, N. 2009. Making family planning accessible in resource-poor settings. Phil. Trans. R. Soc. B, 364, 3093-3099.

Roudi-Fahimi, F., Monem, A. A., Ashford, L. \& ElAdawy, M. 2012. Women's Need for Family Planning in Arab Countries. UNFPA Arab States Regional Office, Pan Arab Project for Family Health(PAPFAM), Population Reference Bureau (PRB).

Sharan, M., Ahmed, S., May, J. \& Soucat, A. $201 \mathrm{I}$. Family Planning Trends in Sub-Saharan Africa: Progress, Prospects, and Lessons Learned. In: PUNAM CHUHUAN-POLE \& MANKA ANQWAFO (eds.) Yes Africa Can: Success Stories from a Dynamic Continent Washington DC: The International Bank for Reconstruction and Development / The World Bank.

Singh, S. \& Darroch, J. E. 2012. Adding It Up: Costs and Benefits of Contraceptive Services Estimates for 2012. New York: Guttmacher Institute and United Nations Population Fund (UNFPA).

StataCorp LP 2009. Stata/SE II.0 for Windows (32bit). 4905 Lakeway Drive, College Station, TX77845, USA.The Central Intelligence Agency 2013. Nigeria The World Factbook. Washington, D.C. 20505.

The William and Flora Hewlett Foundation \& Redstone Strategy Group LLC 2008. Family Planning and Reproductive Health Funding trends and FPRH indicators in Sub-Saharan Africa over the past two decades.

UN Department of Economic and Social Affairs 2007. World Population Policies Population Division.

UNFPA 2013. Population growth and poverty: What are the connections? International Conference on Population and Development (ICPD/I5) 1994-2009. UNFPA.

UNFPA and PATH 2008. Reducing unmet need for family planning: Evidence-based strategies and approaches. Outlook

United Nations 201I. The Millenium Development Goals Report 20I I. New York: United Nations

Westoff, C. 2006. New Estimates of Unmet Need and the Demand for Family Planning. DHS [Demographic and Health Surveys] Comparative Reports. Calverton, MD: Macro International Inc.

Westoff, C. F. 2012. Unmet Need for Modern Contraceptive Methods. In: 28, D. A. S. (ed.). Calverton, Maryland, USA: ICF International.

Wickrama, K. 1990. Use and evaluation of health care services by male and female-headed households in Rural Sri Lanka. . The Journal of Developing Areas, 25, I-I4. 